\title{
Cupaniol, a New Branched Polyprenol, from Cupania latifolia
}

\author{
Wataru Sakane, ${ }^{a}$ Noriyuki Hara, ${ }^{a}$ Yoshinori Fujimoto, $,{ }^{*},{ }^{,}$Yoshihisa Takaishi, ${ }^{b}$ Ricardo Acuña, ${ }^{c}$ \\ Coralia Osorio, ${ }^{d}$ and Carmenza DuQuE ${ }^{d}$ \\ ${ }^{a}$ Department of Chemistry and Materials Science, Tokyo Institute of Technology; Meguro-ku, Tokyo 152-8551, Japan: \\ ${ }^{b}$ Department of Chemistry, Tokushima University; Sho-machi, Tokushima 770-8505, Japan: ${ }^{c}$ Cenicafé, Centro Nacional \\ de Investigaciones del Café; Planalto, Chichiná (Caldas), Colombia: and d Departamento de Química, Universidad \\ Nacional de Colombia; AA 14490, Bogotá, Colombia.
}

Received March 9, 2005; accepted April 18, 2005

\begin{abstract}
A new branched polyprenol, designated cupaniol, has been isolated from the methanol extract of the leaves of Cupania latifolia (Sapindaceae). The structure was determined to be $(2 E, 6 E, 12 E, 16 E)-3,7,13,17,21$-pentamethyl-10-(1-methylethenyl)-2,6,12,16,20-docosapentaen-1-ol on the basis of spectral analysis and conversion to a known compound.
\end{abstract}

Key words cupaniol; Cupania latifolia; Sapindaceae; branched polyprenol

Cupania latifolia KunTH [syn. C. americana subsp. latifolia (Kunth) T. D. Penn., C. papillosa RadlK., and C. sedimentata RADLK.] of the family of Sapindaceae is a mediumsized tree that grows in rainforests of Caribbean countries to Peru in South America. The plant is called guara, mestizo, or guacharaco in Colombia and used to give shade on coffee plantations and for ornamental purposes. The leaves of the related species $C$. americana, which also grows in Mesoamerican rainforests, have been used as a painkiller and the seeds for the treatment of dysentery. ${ }^{1}$ Only a few phytochemical studies on the genera Cupania have been reported. ${ }^{2)}$ To our knowledge, neither $C$. americana nor $C$. latifolia has been chemically investigated. In this paper, we report the isolation and structure elucidation of a new branched polyprenol (1) (Fig. 1), designated cupaniol, from the leaves of C. Latifolia, collected in Manizales, Caldas, Colombia.

\section{Results and Discussion}

Chromatographic separation, including silica gel and Sephadex LH-20 columns, of the ethyl acetate (AcOEt)-soluble part of the methanol $(\mathrm{MeOH})$ extract yielded compound $\mathbf{1}$ as a colorless oil. The molecular formula of $\mathbf{1}$ was determined to be $\mathrm{C}_{30} \mathrm{H}_{50} \mathrm{O}$ on the basis of high-resolution (HR)EI-MS data (observed: 426.3853; $\mathrm{C}_{30} \mathrm{H}_{50} \mathrm{O}$ requires 426.3862). The ${ }^{1} \mathrm{H}-\mathrm{NMR}$ spectrum showed signals of five olefinic protons, exomethylene protons, oxymethylene protons, and seven singlet methyl groups on double bonds, among others. The signal of the oxymethylene protons $(\delta$ 4.15) was coupled to an olefinic proton, as revealed by the $\mathrm{H}-\mathrm{H}$ correlation spectroscopy (COSY) spectrum. The ${ }^{13} \mathrm{C}-$ NMR spectrum displayed 30 peaks that were classified, assisted by distortionless enhancement by polarization transfer (DEPT) experiments, into 12 olefinic carbons, one oxymeth-

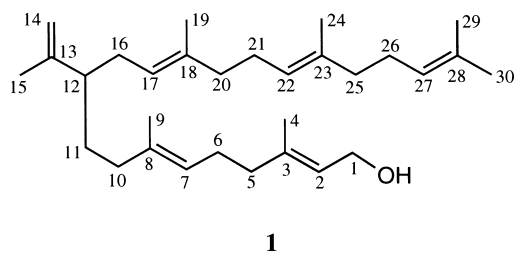

Fig. 1. Chemical Structure of Cupaniol ylene carbon ( $\delta$ 59.37), seven methyl, one aliphatic methine $(\delta$ 47.12), and nine aliphatic methylene carbons. The presence of the $\mathrm{CH}$ carbon was noteworthy. The heteronuclear multiple-bond correlation (HMBC) spectrum allowed connection of the methine carbon (C-12) to an isopropenyl group $(\mathrm{C}-13,-14,-15)$ and an ethylene group $(\mathrm{C}-11,-10)$ (Fig. 2). The connection to the ethylene group was supported by the $\mathrm{H}-\mathrm{H}$ COSY spectrum, which showed cross-peaks between $\mathrm{H}-12$ and $\mathrm{H}_{2}-11\left(\delta_{\mathrm{H}} 1.38,1.46, \delta_{\mathrm{C}} 31.01\right)$, and between $\mathrm{H}_{2}-11$ and $\mathrm{H}_{2}-10\left(\delta_{\mathrm{H}} 1.9, \delta_{\mathrm{C}} 37.40\right)$. The $\mathrm{C}-10$ was

Table 1. ${ }^{1} \mathrm{H}$ - and ${ }^{13} \mathrm{C}-\mathrm{NMR}$ Data for $\mathbf{1}\left(500 / 125 \mathrm{MHz}, \mathrm{CDCl}_{3}\right)$

\begin{tabular}{|c|c|c|c|}
\hline C no. & ${ }^{1} \mathrm{H}$ & ${ }^{13} \mathrm{C}$ & $\mathrm{HMBC}$ correlation from $\mathrm{H}$ to $\mathrm{C}$ \\
\hline 1 & $4.15(\mathrm{~d}, J=6.9 \mathrm{~Hz})$ & $59.37\left(\mathrm{CH}_{2}\right)$ & $\mathrm{C}-2, \mathrm{C}-3$ \\
\hline 2 & $5.41(\mathrm{t}, J=6.9 \mathrm{~Hz})$ & $123.26(\mathrm{CH})$ & C-1, C-4, C-5 \\
\hline 3 & - & $139.80(\mathrm{C})$ & \\
\hline 4 & $1.68(\mathrm{~s})$ & $16.17\left(\mathrm{CH}_{3}\right)$ & $\mathrm{C}-2, \mathrm{C}-3, \mathrm{C}-5$ \\
\hline 5 & $1.94-2.12(\mathrm{~m})$ & $39.54\left(\mathrm{CH}_{2}\right)$ & $\mathrm{C}-2, \mathrm{C}-3, \mathrm{C}-4$ \\
\hline 6 & $1.94-2.12(\mathrm{~m})$ & $26.25\left(\mathrm{CH}_{2}\right)^{a)}$ & f) \\
\hline 7 & $5.07-5.12(\mathrm{~m})$ & $123.54(\mathrm{CH})^{b)}$ & $\mathrm{C}-10^{f)}$ \\
\hline 8 & - & $135.62(\mathrm{C})$ & \\
\hline 9 & $1.58(\mathrm{~s})$ & $15.97\left(\mathrm{CH}_{3}\right)$ & $\mathrm{C}-7, \mathrm{C}-8, \mathrm{C}-10$ \\
\hline 10 & $1.9(\mathrm{~m})$ & $37.40\left(\mathrm{CH}_{2}\right)$ & C-7, C-8, C-9, C-11, C-12 \\
\hline 11 & $1.38 / 1.46(\mathrm{~m})$ & $31.01\left(\mathrm{CH}_{2}\right)$ & C-10, C-12, C-13 \\
\hline 12 & $1.94-2.12(\mathrm{~m})$ & $47.12(\mathrm{CH})$ & C-13, C-14, C-15 \\
\hline 13 & - & $147.66(\mathrm{C})$ & \\
\hline 14 & $4.65(\mathrm{~s}), 4.74(\mathrm{~s})$ & $111.23\left(\mathrm{CH}_{2}\right)$ & C-12, C-13, C-15 \\
\hline 15 & $1.61(\mathrm{~s})$ & $18.55\left(\mathrm{CH}_{3}\right)$ & $\mathrm{C}-12, \mathrm{C}-13, \mathrm{C}-14$ \\
\hline 16 & $1.94-2.12(\mathrm{~m})$ & $32.14\left(\mathrm{CH}_{2}\right)$ & $\mathrm{C}-11, \mathrm{C}-12, \mathrm{C}-13$ \\
\hline 17 & $5.07-5.12(\mathrm{~m})$ & $123.04(\mathrm{CH})^{b)}$ & $\mathrm{C}-12, \mathrm{C}-16$ \\
\hline 18 & - & $135.35(\mathrm{C})^{c)}$ & \\
\hline 19 & $1.59(\mathrm{~s})$ & $15.97\left(\mathrm{CH}_{3}\right)^{d)}$ & f) \\
\hline 20 & $1.94-2.12(\mathrm{~m})$ & $39.77\left(\mathrm{CH}_{2}\right)^{e)}$ & f) \\
\hline 21 & $1.94-2.12(\mathrm{~m})$ & $26.63\left(\mathrm{CH}_{2}\right)^{a)}$ & f) \\
\hline 22 & $5.07-5.12(\mathrm{~m})$ & $124.21(\mathrm{CH})$ & f) \\
\hline 23 & - & $134.84(\mathrm{C})^{c}$ & \\
\hline 24 & $1.59(\mathrm{~s})$ & $16.25\left(\mathrm{CH}_{3}\right)^{d)}$ & f) \\
\hline 25 & $1.94-2.12(\mathrm{~m})$ & $39.70\left(\mathrm{CH}_{2}\right)^{e)}$ & f) \\
\hline 26 & $1.94-2.12(\mathrm{~m})$ & $26.74\left(\mathrm{CH}_{2}\right)^{a)}$ & f) \\
\hline 27 & $5.07-5.12(\mathrm{~m})$ & $124.37(\mathrm{CH})$ & $\mathrm{C}-29, \mathrm{C}-30$ \\
\hline 28 & - & $131.22(\mathrm{C})$ & \\
\hline 29 & 1.605 & $17.67\left(\mathrm{CH}_{3}\right)$ & $\mathrm{C}-27, \mathrm{C}-28, \mathrm{C}-30$ \\
\hline 30 & $1.68(\mathrm{~s})$ & $25.69\left(\mathrm{CH}_{3}\right)$ & $\mathrm{C}-27, \mathrm{C}-28, \mathrm{C}-29$ \\
\hline
\end{tabular}

$a-e)$ Interchangeable. $f$ ) Expected correlations were observed, but it was difficult to assign them due to overlapping of proton and/or carbon signals. 


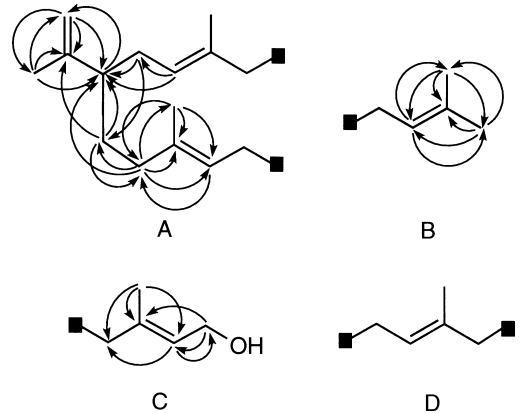

Fig. 2. Partial Structures for Cupaniol as Revealed by 2D-NMR Studies Arrows represent HMBC correlations $(\mathrm{H} \rightarrow \mathrm{C})$.
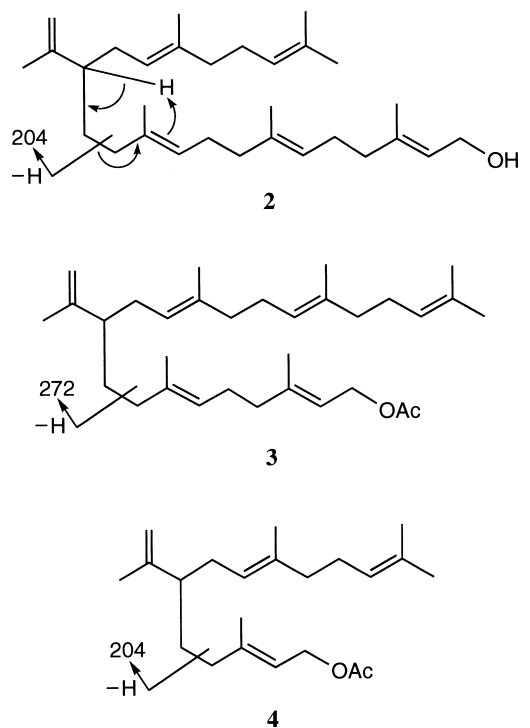

Fig. 3. Reported Intense Fragment Ions for $\mathbf{3}$ and 4, and an Expected Fragment Ion for $\mathbf{2}$

suggested to be a carbon of a prenyl unit (C-6 to C-10), since a methyl group $\left(\delta_{\mathrm{H}} 1.58, \mathrm{H}_{3}-9\right)$ was correlated with the $\mathrm{C}-10$ carbon and two olefinic carbons at $135.62(\mathrm{C}-8)$ and 123.54 $(\mathrm{C}-7)$. In addition, $\mathrm{H}-12$ was further correlated with $\mathrm{C}-16\left(\delta_{\mathrm{C}}\right.$ $32.14)$ and $\mathrm{C}-17\left(\delta_{\mathrm{C}} 123.04\right)$ in the HMBC and $\mathrm{H}-\mathrm{H}$ COSY spectra. Another prenyl unit involving C-16 and C-17 could be incorporated into the partial structure $\mathbf{A}$, since $\mathrm{HMBC}$ correlations from a methyl group $\left(\mathrm{H}_{3}-19\right)$ to $\mathrm{C}-17, \mathrm{C}-18$, and $\mathrm{C}-20$ were observed. The presence of the two terminal isoprene units $\mathbf{B}$ and $\mathbf{C}$ was readily deduced from the HMBC correlations depicted in Fig. 2. The three partial structures A- C accounted for 25 carbons of the molecule, thus suggesting the presence of yet another prenyl unit $\mathbf{D}$. A linear combination of the four partial structures, keeping in mind the biosynthetic isoprene rule, would give rise to the two possible structures 1 and 2 (Fig. 3) for cupaniol.

Although analysis of the NMR data did not afford further information on the structure, the EI-MS spectrum provide a clue as to whether $\mathbf{1}$ or $\mathbf{2}$ is the correct structure of cupaniol. Fortunately, EI-MS fragmentation patterns of synthetic related compounds $\mathbf{3}$ and $\mathbf{4}$ were reported previously: An intense fragment ion due to McLafferty rearrangement was observed at $\mathrm{m} / z 272$ and 204 for compounds 3 and $\mathbf{4}$, respectively. ${ }^{3)}$ It is therefore expected that structure 1 should afford an intense fragment ion at $\mathrm{m} / \mathrm{z} 272$ (see Fig. 4), while struc-
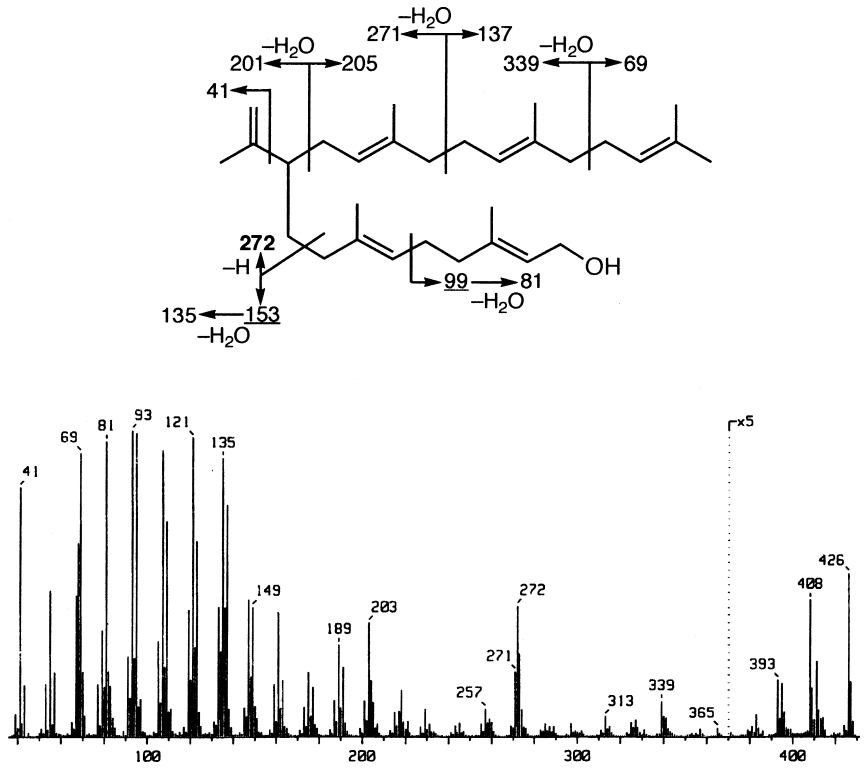

Fig. 4. EI-MS $(70 \mathrm{eV})$ Spectrum and Fragmentation Pattern of Compound

The underlined fragment ions could not be observed.

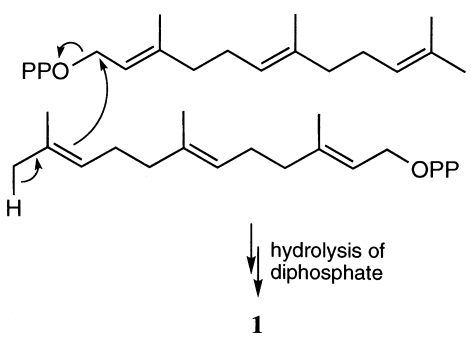

Fig. 5. Postulated Biosynthesis of Compound $\mathbf{1}$

OPP represents diphosphate group.

ture 2 should yield an ion at $m / z 204$ (Fig. 3). The EI-MS of cupaniol is illustrated in Fig. 4, which clearly shows a fragment ion at $\mathrm{m} / \mathrm{z} 272$ (HR-EI-MS $\mathrm{m} / \mathrm{z}: 272.2520 ; \mathrm{C}_{20} \mathrm{H}_{32}$ requires 272.2502), consistent with the structure 1 . The presense of the $\mathrm{m} / \mathrm{z} 272$ ion in the trimethylsilyl ether derivative of 1 further supported the interpretation of the ion. ${ }^{4}$ The mass fragmentation of $\mathbf{1}$ is summarized in Fig. 4. The geometry of the double bond, i.e., $\Delta^{2}, \Delta^{7}, \Delta^{17}$, and $\Delta^{22}$ was determined to be all trans by comparing the ${ }^{13} \mathrm{C}$ data with those of relevant polyprenols. ${ }^{5}$ Hence the structure of cupaniol was determined to be $\mathbf{1}$ as shown in Fig. $1{ }^{6}{ }^{6}$ Cupaniol had $[\alpha]_{\mathrm{D}}$ $+2.5^{\circ}\left(c=2.1, \mathrm{CHCl}_{3}\right)$, suggesting that this natural product is optically active, although the absolute configuration was not investigated. Finally, compound $\mathbf{1}$ was converted to the corresponding acetate, which was reported as a synthetic material. ${ }^{3)}$ The NMR and MS data of cupaniol acetate were in excellent agreement with the reported values.

Cupaniol $\mathbf{1}$ is a branched polyprenol. The simplest natural compound of this class is lavandulol, a dimer of isopentenol which occurs frequently in essential oils, ${ }^{7,8)}$ and cupaniol can be regarded as a higher homologue of lavandulol. There are a few examples of such higher homologues that were subjected to further modifications. ${ }^{9,10)}$ Hydrocarbon forms (arising from elimination of water and/or saturation and unsaturation) of related branched isoprenoids have been also reported in 
coastal and deep-sea marine sediments ${ }^{11,12)}$ and benthic diatoms. ${ }^{13)}$ Biogenesis of 1 can be outlined as shown in Fig. 5.

In addition to cupaniol, ficaprenol $12,{ }^{14,15)} \alpha$ - and $\beta$-tocopherols, ${ }^{16)} \beta$-amyrin, ${ }^{17)}$ and taraxerol ${ }^{17)}$ were isolated from the AcOEt-soluble fraction and characterized by comparing the NMR and MS data with the reported values, while (-)epicatechin $^{18,19)}$ and proanthocyanidin $\mathrm{A} 2^{20)}$ were isolated from the AcOEt-insoluble fraction of the $\mathrm{MeOH}$ extract.

\section{Experimental}

General ${ }^{1} \mathrm{H}$ - and ${ }^{13} \mathrm{C}$-NMR spectra were obtained on a Bruker DRX500 $\left(500 \mathrm{MHz}\right.$ for ${ }^{1} \mathrm{H}$ and $125 \mathrm{MHz}$ for ${ }^{13} \mathrm{C}$ ) spectrometer in $\mathrm{CDCl}_{3}$ solutions with tetramethylsilane (TMS) as an internal reference. Chemical shifts are expressed in $\delta(\mathrm{ppm})$, referring to TMS $\left(\delta_{\mathrm{H}} 0.00\right)$ and the solvent signal $\left(\delta_{\mathrm{C}}\right.$ $77.00)$. EI-MS $(70 \mathrm{eV})$ spectra were obtained on a JEOL JMS-700 spectrometer in a direct inlet method. Optical rotations were measured on a JASCO DIP-360 polarimeter. Silica gel chromatography was carried out using Kieselgel 60 (E. Merck). HPLC was performed on a Shimadzu LC-6A instrument with an SPD-6A UV detector, using an ODS column (Shim-Pack CLC-ODS, $15 \mathrm{~cm} \times 6 \mathrm{~mm}$ i.d.)

Plant Material The leaves of C. americana were collected in October 2002 at Manizales, Caldas, Colombia. The plant was identified by Dr. Julio Betancur and a specimen voucher (No. COL495137) was deposited at the Instituto de Ciencias Naturales de la Universidad Nacional de Colombia.

Extraction and Isolation The air-dried leaves $(1.0 \mathrm{~kg})$ were extracted with methanol two times under reflux for $2 \mathrm{~h}$. The concentrated $\mathrm{MeOH}$ $(151 \mathrm{~g})$ was shaken with $\mathrm{AcOEt}(400 \mathrm{ml} \times 2)$ to give the AcOEt-soluble fraction $(45 \mathrm{~g})$ after removal of the solvent. This was chromatographed on silica gel with hexane-AcOEt. The fraction eluted with hexane-AcOEt $(6: 1)$ was chromatographed again under similar conditions. The resulting residue was separated on Sephadex LH-20 with AcOEt-CHCl $(1: 1)$ as an eluent. The fraction enriched with compound $\mathbf{1}$ was finally separated by preparative TLC with hexane-AcOEt $(7: 1)$ as a developing solvent to yield $\mathbf{1}$ as a colorless oil ( $31 \mathrm{mg}, 0.031 \%$ yield based on the air-dried leaves). Spectral data for $\mathbf{1}$ are described in the text.

The fractions eluted with hexane-AcOEt $(10: 1-8: 1)$ in the above first chromatography were further chromatographed over silica gel and then separated on Sephadex LH-20 with hexane-AcOEt $(1: 1)$ to give ficaprenol 12 $(150 \mathrm{mg})$. The fractions eluted with hexane-AcOEt $(8: 1-7: 1)$ were further chromatographed on Sephadex LH-20 with AcOEt-CHCl ${ }_{3}(1: 1)$ and then separated by preparative TLC with hexane-ether $(10: 1)$ as a developing solvent to give partially purified $\alpha$-tocopherol $(7.5 \mathrm{mg})$ and $\beta$-tocopherol fractions. Final purification of the fractions by HPLC with methanol as an eluting solvent gave $\alpha$-tocopherol $(7.5 \mathrm{mg})$ and $\beta$-tocopherol $(84 \mathrm{mg})$. The fractions eluted with hexane-AcOEt $(7: 1-6: 1)$ were further chromatographed over silica gel and then separated on Sephadex LH-20 with $\mathrm{CHCl}_{3}-\mathrm{MeOH}(2: 3)$ to give a mixture of $\beta$-amyrin and taraxerol. The two triterpenes were finally separated by HPLC with methanol-THF $(10: 1)$ as an eluting solvent to yield $\beta$-amyrin $(50 \mathrm{mg})$ and taraxerol $(45 \mathrm{mg})$. The AcOEt-insoluble fraction of the original extract was chromatographed over silica gel with $\mathrm{CHCl}_{3}-\mathrm{MeOH}$. The fractions eluted with $\mathrm{CHCl}_{3}-\mathrm{MeOH}$
( $4: 1)$ were further separated on Sephadex LH-20 with $\mathrm{CHCl}_{3}-\mathrm{MeOH}(2: 3)$ to give (-)-epicatechin $(60 \mathrm{mg})$. The fractions eluted with $\mathrm{CHCl}_{3}-\mathrm{MeOH}$ $(3: 1)$ were further separated on Sephadex LH-20 with $\mathrm{CHCl}_{3}-\mathrm{MeOH}(2: 3)$ to give proanthocyanidin A2 $(405 \mathrm{mg})$.

Acknowledgments This study was supported by a grant-in-aid from the Ministry of Education, Science, Sports, Culture and Technology of Japan (No. 12576030), and from the Ministry of Environment, Housing and Territorial Development of Colombia and the National Coffee Growers of Colombia (Contract No. 21/2002). Thanks are also due to Dr. Julio Betancur for the identification of the plant.

\section{References and Notes}

1) Francis J. K., “Cupania americana L. Guara. SO-ITF-SM-544,” US Department of Agriculture, Forest Service, Southern Forest Experiment Station, New Orleans, 1991, pp. 1-4.

2) Cavalcanti S. B. T., Teles H. L., Silva D. H. S., Furlan M., Young M., Claudia M., Bolzani V. S., J. Brazilian Chem. Soc., 12, 413-416 (2001).

3) Nagano H., Nakanishi E., Takajo S., Sakuma M., Kudo K., Tetrahedron, 55, 2591-2608 (1999).

4) EI-MS of the trimethylsilyl ether derivative of $1: \mathrm{m} / \mathrm{z} 498\left(\mathrm{M}^{+}, 5 \%\right)$, 483 (2), 429 (1), 408 (5), 272 (11), 271 (13), 255 (10), 203 (14), 156 (20), 135 (24), 121 (28), 81 (57), 69 (100), 55 (20), 41 (23).

5) "Carbon-13 NMR Spectroscopy," Chap. 5, ed. by Breitmaier E., Voelter W., VCH Verlagssgesellschaft, Weinheim, 1987.

6) IUPAC name: $(2 E, 6 E, 12 E, 16 E)-3,7,13,17,21$-pentamethyl-10-(1methylethenyl)-2,6,12,16,20-docosapentaen-1-ol.

7) Schinz H., Seidel C. F., Helv. Chim. Acta, 25, 1572-1591 (1942).

8) Barazandeh M. M., J. Essential Oil Res., 14, 103-104 (2002).

9) Mangoni L., Merola D., Monaco P., Parrilli M., Previtera L., Tetrahedron Lett., 25, 2597-2600 (1984).

10) Bousserouel H., Litaudon M., Morleo B., Martin, Thoison O., Nosjean O., Boutin J. A., Renard P., Sevenet T., Tetrahedron, 61, 845-851 (2005).

11) Robson J. N., Rowland S. J., Nature (London), 324, 561—563 (1986).

12) Belt S. T., Cooke D. A., Hird S. J., Rowland S., J. Chem. Soc., Chem. Commun., 1994, 2077-2078 (1994).

13) e.g., Belt S. T., Masse G., Allard W. G., Robert J.-M., Rowland S. J., Organic Geochemistry, 32, 1271-1275 (2001).

14) Suga T., Ohta S., Nakai A., Munesada K., J. Org. Chem., 54, 33903393 (1989).

15) Aoki T., Matsuo K., Suga T., Ohta S., Phytochemistry, 46, 715-720 (1997).

16) Strohschein S., Pursch M., Lubda D., Albert K., Anal. Chem., 70, 1318 (1998).

17) Takasaki M., Konoshima T., Tokuda H., Masuda K., Arai Y., Shiojima K., Ageta H., Biol. Pharm. Bull., 22, 606-610 (1999).

18) Shen C.-C., Chang Y.-S., Ho L.-K., Phytochemistry, 34, 843-845 (1993).

19) Foo L.-Y., Karchesy J. J., Phytochemistry, 28, 1743-1747 (1989).

20) Lou H., Yamazaki Y., Sasaki T., Uchida M., Tanaka H., Oka S., Phytochemistry, 51, 297-308 (1999). 